UCRL-ID-127650

\title{
Summary of the Cost Analysis Report for the Long-Term Management of Depleted Uranium Hexafluoride
}

\author{
J. W. Dubrin \\ L. Rahm-Crites
}

Prepared for the Department of Energy by Lawrence Livermore National Laboratory

September 1997

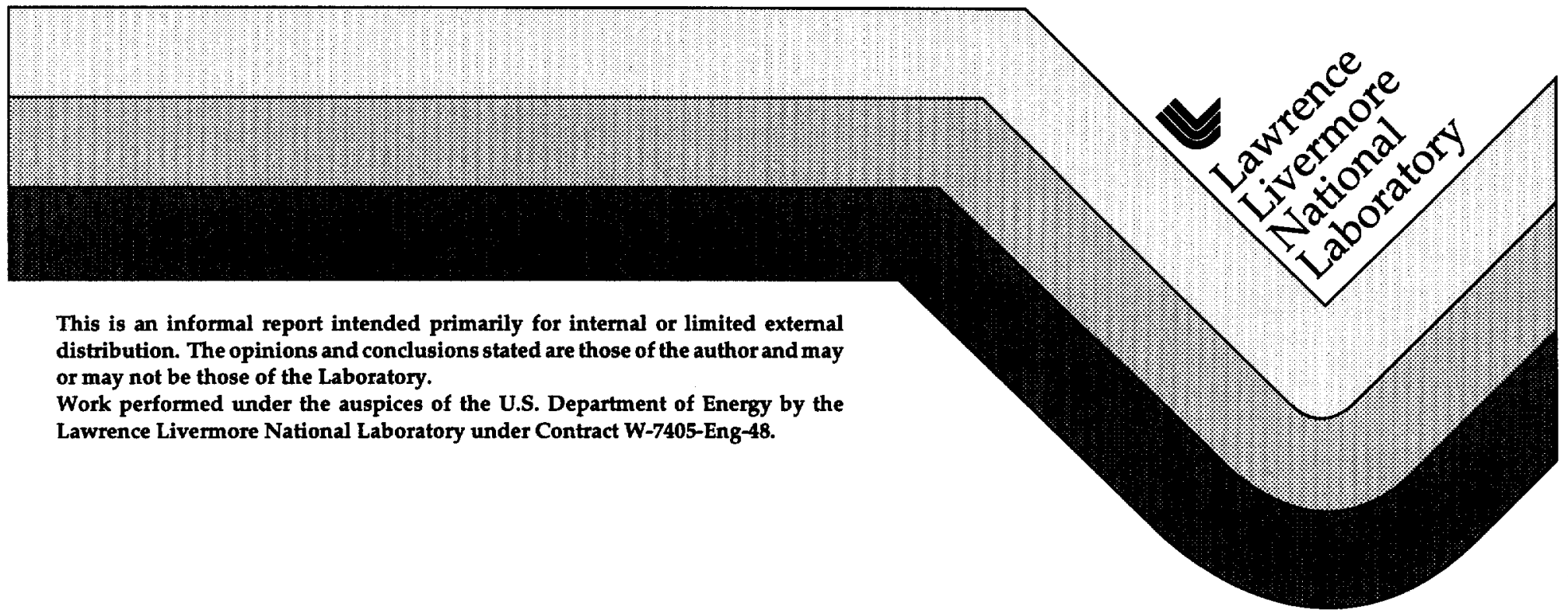




\section{DISCLAIMER}

This document was prepared as an account of work sponsored by an agency of the United States Government. Neither the United States Government nor the University of California nor any of their employees, makes any warranty, express or implied, or assumes any legal liability or responsibility for the accuracy, completeness, or usefulness of any information, apparatus, product, or process disclosed, or represents that its use would not infringe privately owned rights. Reference herein to any specific commercial product, process, or service by trade name, trademark, manufacturer, or otherwise, does not necessarily constitute or imply its endorsement, recommendation, or favoring by the United States Government or the University of California. The views and opinions of authors expressed herein do not necessarily state or reflect those of the United States Government or the University of California, and shall not be used for advertising or product endorsement purposes.

This report has been reproduced directly from the best available copy.

Available to DOE and DOE contractors from the Office of Scientific and Technical Information

P.O. Box 62, Oak Ridge, TN 37831

Prices available from (615) 576-8401, FTS 626-8401

Available to the public from the

National Technical Information Service

U.S. Department of Commerce

5285 Port Royal Rd.,

Springfield, VA 22161 


\section{Summary of the COST ANAL YSIS REPORT for the Long-Term Management of Depleted Uranium Hexafluoride}

Note: This Summary condenses and simplifies a number of technical issues and ideas. To obtain a fuller understanding of particular issues and ideas, the reader is urged to consult the complete Cost Analysis Report.

\section{Introduction}

The Department of Energy is analyzing the environmental impacts and costs of possible strategies for the long-term management and use of its depleted uranium hexafluoride.

The Department of Energy (DOE) owns about 560,000 metric tons (over a billion pounds) of depleted uranium hexafluoride $\left(\mathrm{UF}_{6}\right)$. This material is contained in steel cylinders located in storage yards near Paducah, Kentucky, and Portsmouth, Ohio, and at the East Tennessee Technology Park (formerly the K-25 Site) in Oak Ridge, Tennessee.

Uranium hexafluoride $\left(\mathrm{UF}_{6}\right)$ is a compound of one part uranium to six parts fluorine. At room temperature, it is a white solid similar to rock salt. It is usually measured in metric tons (MT). One MT equals about 2200 pounds.

On November 10, 1994, DOE announced its new Depleted

Uranium Hexafluoride Management Program by issuing a Request for Recommendations and an Advance Notice of Intent in the Federal Register (59 FR 56324 and 56325). The first part of this Program consists of engineering, cost, and environmental impact studies. Part one will conclude with the selection of a long-term management plan, or strategy. Part two will carry out the selected strategy.

DOE's depleted $\mathrm{UF}_{6}$ is stored in a partial vacuum inside steel cylinders. Most cylinders are about twelve feet long and 48 inches in diameter and hold between nine and twelve MT of solid depleted $\mathrm{UF}_{6}$. In all, there are 46,422 cylinders. The current management strategy is to continue safe storage

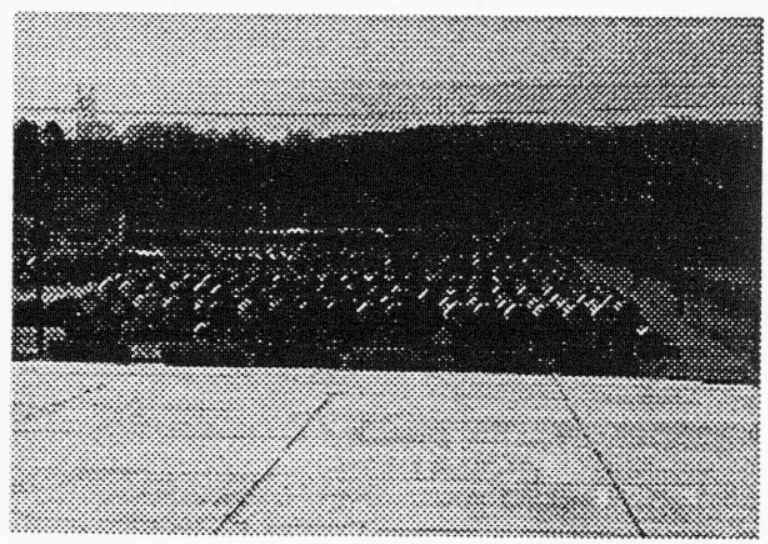

Depleted $U F_{\sigma}$ is stored in cylinder yards like this one at Portsmouth. 
of the depleted $\mathrm{UF}_{6}$ cylinders in the existing storage yards. Activities in this strategy include inspection, handling, monitoring, and maintenance, as needed, to keep the cylinders in good condition.

The Draft Programmatic Environmental Impact Statement (Draft PEIS) looks at six alternative strategies for the long-term management of depleted $\mathrm{UF}_{6}$. They include the current management strategy (the "No Action alternative"), two alternatives for long-term storage, two alternatives for use, and one for disposal. DOE's preferred alternative is to use 100 percent of the depleted uranium, either as uranium oxide or uranium metal, or a combination of both. The fluorine in the depleted $\mathrm{UF}_{6}$ would also be used.

The Cost Analysis Report provides comparative cost data for the management strategy alternatives. The PEIS and the Cost Analysis Report will help DOE select a management strategy. The Record of Decision, expected in 1998, will complete the first part of the Depleted Uranium Hexafluoride Management Program. The second part of the Program will look at specific sites and technologies for carrying out the selected strategy.

The Cost Analysis Report estimates the primary capital and operating costs for the different alternatives. It reflects the costs of technology development, construction of facilities, operation, and decontamination and decommissioning. It also includes potential revenues from the sale of byproducts such as anhydrous hydrogen fluoride (AHF). These estimates are based on early designs. They are intended to help in comparing alternatives, rather than to indicate absolute costs for project budgets or bidding purposes. More detailed estimates and specific funding sources will be considered in part two of the Depleted Uranium Hexafluoride Management Program.

The technical data upon which the cost analysis is based are mainly located in the Engineering Analysis Report. Readers are urged to review the Engineering Analysis Report or the Summary of the Engineering Analysis Report to obtain background information for understanding the cost analysis.

\section{Options and Alternative Management Strategies}

The cost analysis looks at the options and suboptions which make up possible management strategies.

\subsection{How Management Strategy Alternatives Were Developed}

A cost breakdown structure (Figure 1) was prepared to provide an orderly way to compare the different management strategies. The cost breakdown structure is patterned after the work breakdown structure in the Engineering Analysis Report, but it adds a sixth module, "continued cylinder storage/current management." This activity is in practice at the three current storage sites and is included in the cost estimates. 


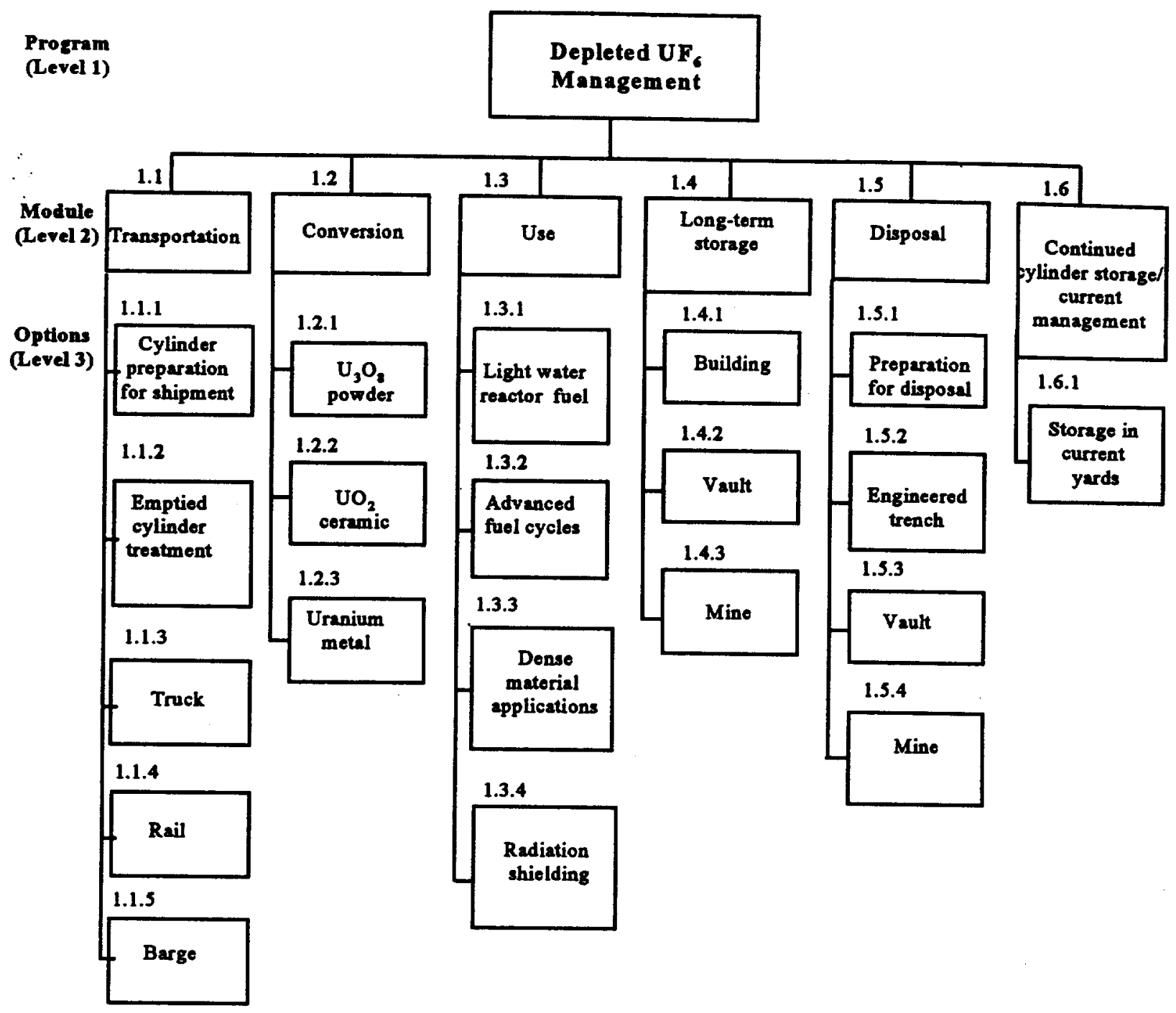

\section{Figure 1. Depleted UF 6 Cost Breakdown Structure, Showing Modules (Level 2) and Options (Level 3)}

Figure 1 shows the modules (Level 2) and the options (Level 3) that are the building blocks for the management strategy alternatives. In most cases, a complete management strategy will combine two or more of the six modules: transportation, conversion, use, long-term storage, disposal, and continued cylinder storage/current management. For example, continued cylinder storage/current management is the first step in all management strategies. Conversion of the depleted $\mathrm{UF}_{6}$ to another chemical form is involved in the use and disposal alternatives and in one of the long-term storage alternatives. Transportation of materials occurs in all strategies except the No Action alternative. 
As shown in Figure 1, Level 3, there are various options within each module. For example, in the long-term storage module there are three different options for the type of facility in which the depleted uranium could be stored: building, vault, and mine.

The next level of detail after options is called suboptions. For example, the long-term storage facility types are further broken down by the forms of depleted uranium which might be stored in each. The suboptions for each option are shown in Table 1.

Table 1. Options and Suboptions for the Various Modules

(Note: shaded boxes are principal options and suboptions analyzed in less detail)

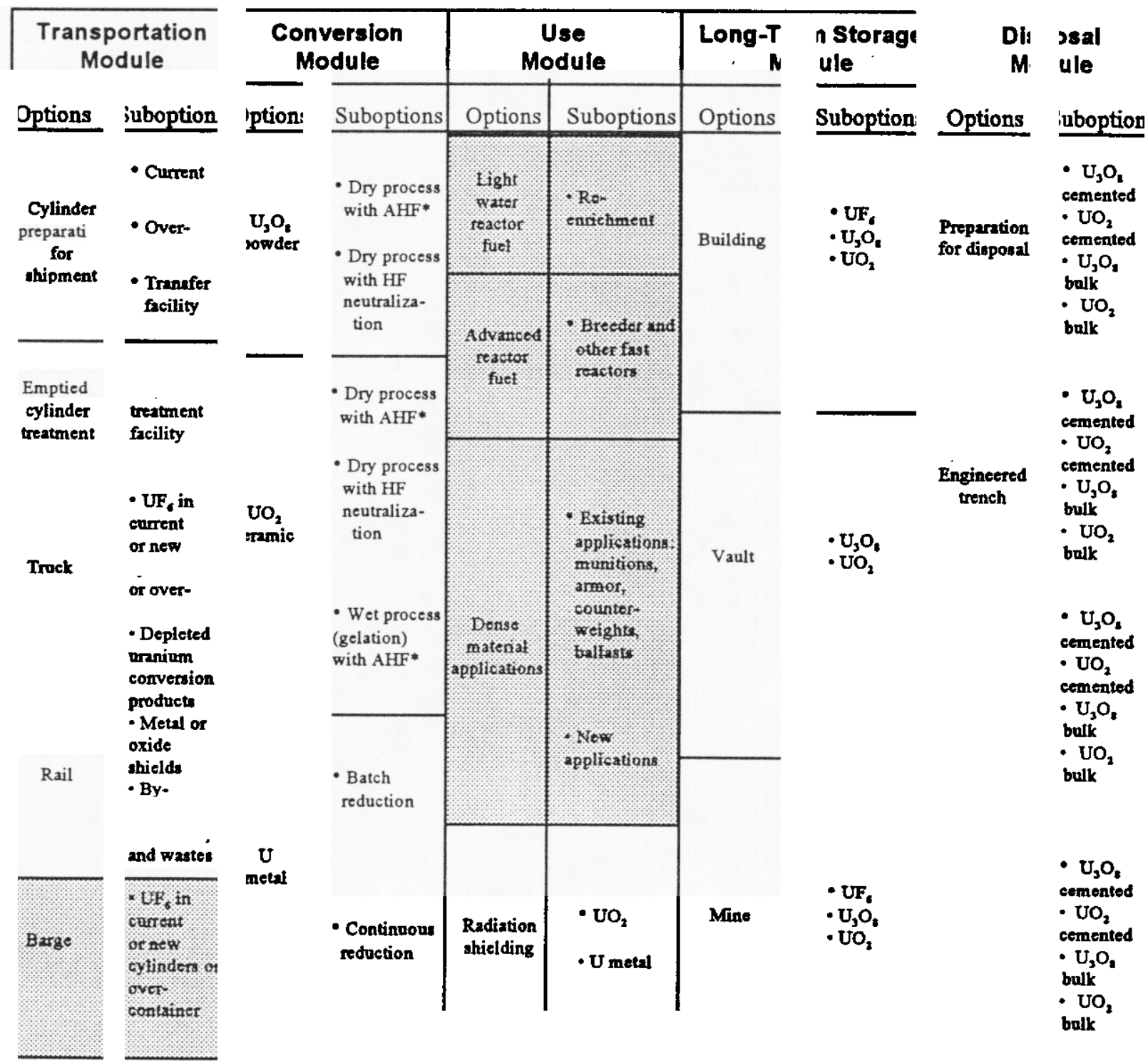


Figures 2 through 7 illustrate the management strategy alternatives analyzed in the PEIS. They show how options and suboptions from the various modules can be combined to build complete management strategies. Note that these figures provide examples only, rather than exact descriptions of how the alternatives would be carried out.
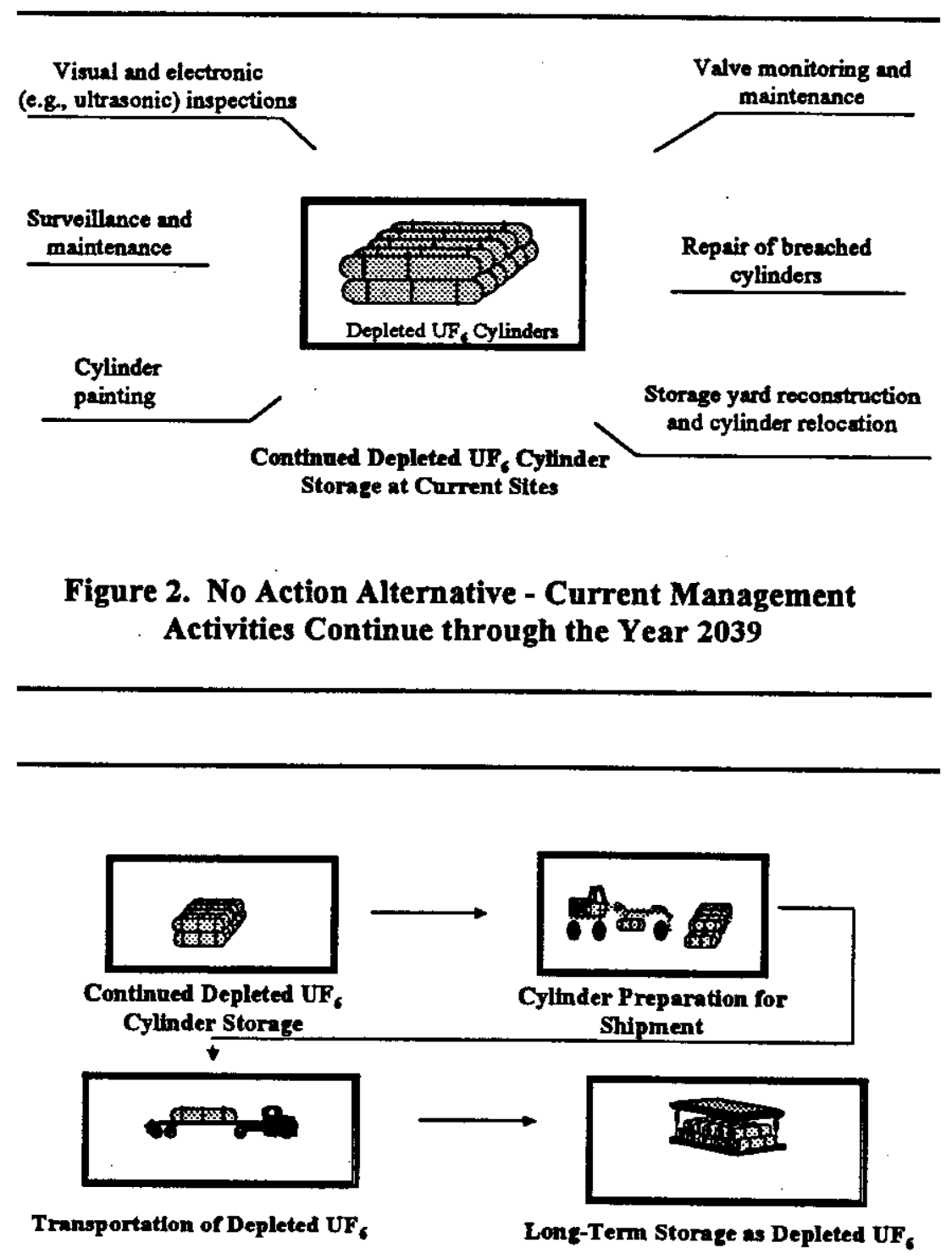

Figure 3. Long-Term Storage as Depleted UF, 


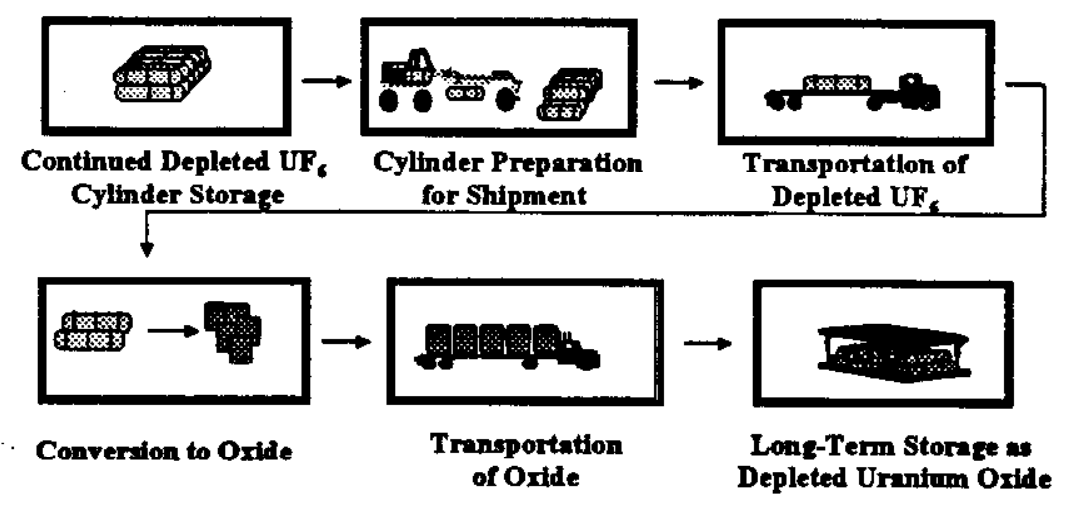

Figure 4. Long-Term Storage as Depleted Uranium Oxide

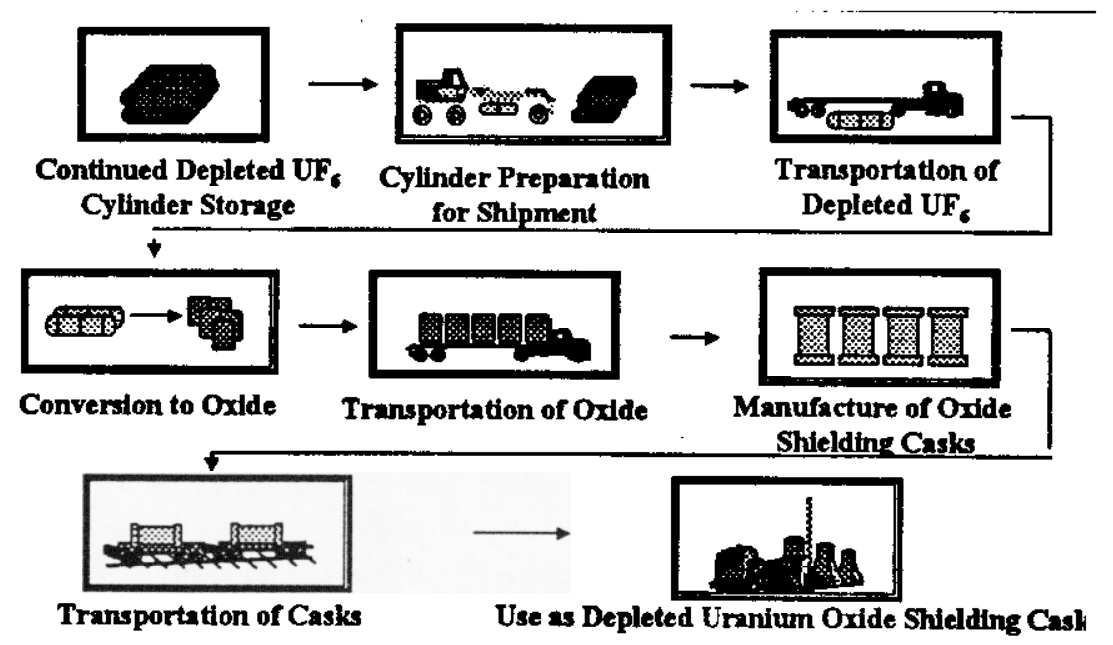

Figure 5. Use as Depleted Uranium Oxide 


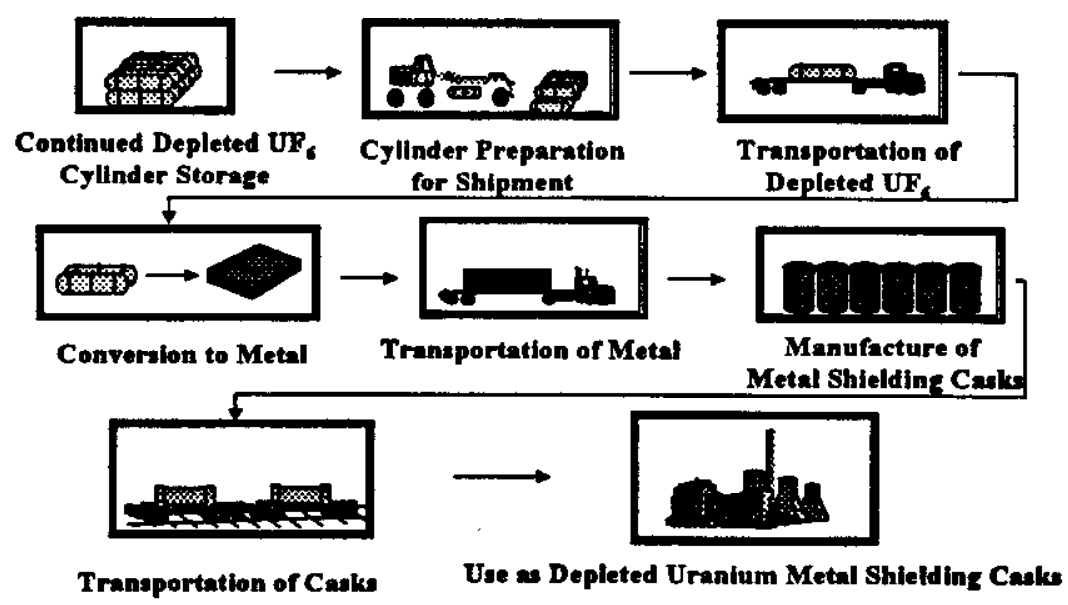

Figure 6. Use as Depleted Uranium Metal

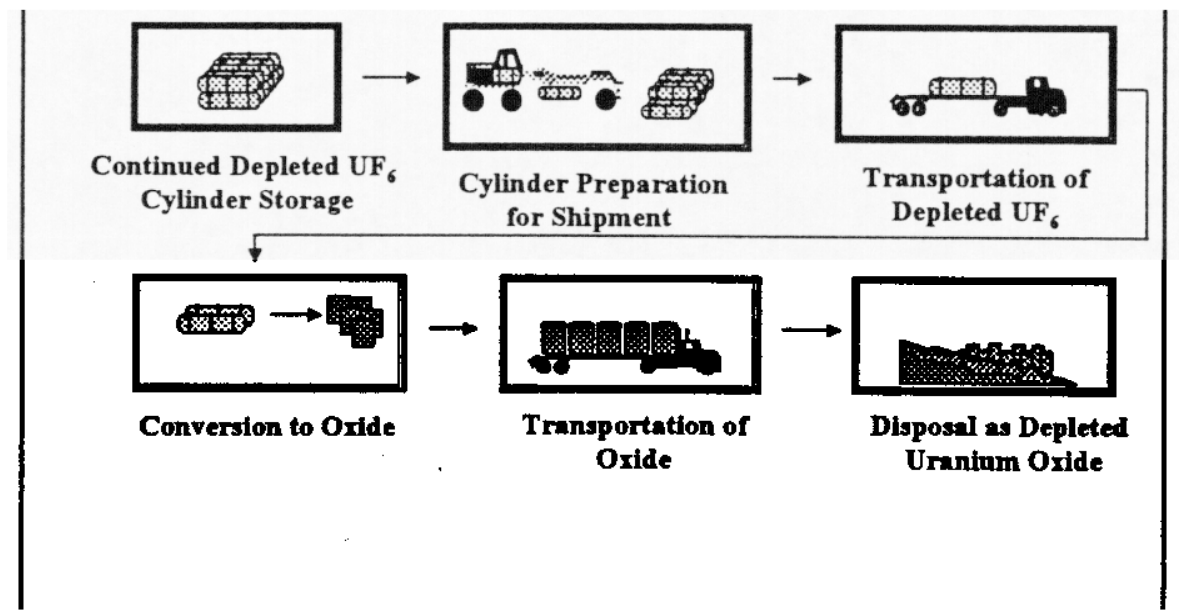

Figure 7. Disposal as Depleted Uranium Oride 


\subsection{Descriptions of Options and Suboptions}

This section briefly describes the options and suboptions listed in the unshaded boxes in Table 1 . The module for continued cylinder storage/current management at existing sites is also described.

Continued Depleted $\mathrm{UF}_{6}$ Cylinder Storage/Current Management. Continued cylinder storage at the current sites is the first activity for all alternatives. In the No Action alternative, it is the only activity. Figure 2 lists the major actions which occur during continued cylinder storage.

Transportation. Except for the No Action alternative, all alternatives involve transportation. The analysis assumes that cylinders of depleted $\mathrm{UF}_{6}$ will be transported from their current locations and that conversion, use, long-term storage and disposal will take place at different sites. Transportation activities may occur at various points in a management strategy. Facility locations will be determined in part two of the Program; therefore, this analysis assumes a representative distance of 1000 kilometers $(\mathrm{km})$, or 620 miles, per trip.

Cylinder preparation for shipment refers to the work required to prepare the depleted $\mathrm{UF}_{6}$ cylinders for transportation from the three current storage sites. Offsite transportation of cylinders is regulated by the Department of Transportation (DOT). These regulations involve (1) the amount of depleted $\mathrm{UF}_{6}$ inside the cylinder, (2) the pressure inside the cylinder, and (3) the condition of the cylinder, especially the thickness of the steel walls. Cylinders that meet DOT requirements would need only minimal preparation and could be shipped whenever desired. Some cylinders, however, would require additional work to meet the DOT regulations. Two preparation suboptions for these nonconforming cylinders are analyzed: either the cylinder might be placed inside an overcontainer or the depleted $\mathrm{UF}_{6}$ might be transferred to a new cylinder.

Emptied cylinder treatment refers to what is done to a cylinder after the depleted $\mathrm{UF}_{6}$ has been removed, usually for conversion. The inside of the cylinder is washed with water and the water is evaporated. The uranium in the remaining depleted $\mathrm{UF}_{6}$ is converted to solid uranium oxide and the fluorine is converted to calcium fluoride $\left(\mathrm{CaF}_{2}\right)$ for disposal. It is assumed that these cleaned cylinders will be added to the scrap metal at the current storage sites.

Conversion. In most of the management strategy alternatives, the depleted $\mathrm{UF}_{6}$ would be converted to another chemical form. The analysis considers three options: (1) conversion to triuranium octaoxide $\left(\mathrm{U}_{3} \mathrm{O}_{8}\right)$ powder, (2) conversion to uranium dioxide $\left(\mathrm{UO}_{2}\right)$ ceramic, and (3) conversion to uranium metal. A number of technology suboptions are analyzed. They are briefly described below.

Two "dry" processes, which use steam instead of water, are analyzed for conversion to $\mathrm{U}_{3} \mathrm{O}_{8}$ powder. Large quantities of hydrogen fluoride (HF) are produced during these processes. The difference between the two suboptions is that one converts the HF into anhydrous HF (AHF) and the other combines the HF with lime (or neutralizes it) to form calcium fluoride $\left(\mathrm{CaF}_{2}\right)$. 
Three suboptions are analyzed for conversion to ceramic $\mathrm{UO}_{2}$. Two of these are dry processes which produce pellets of about two centimeters $(3 / 4 \mathrm{inch})$ in diameter. In one of these suboptions AHF is produced, and in the other the HF is neutralized, as above. A third suboption for conversion to ceramic $\mathrm{UO}_{2}$ uses a wet process known as "gelation." Gelation produces very tiny spheres of about one millimeter (about $1 / 20$ inch) or less in diameter.

The two processes analyzed for converting depleted $\mathrm{UF}_{6}$ to uranium metal both use magnesium $(\mathrm{Mg})$. After depleted $\mathrm{UF}_{6}$ is converted to depleted uranium tetrafluoride $\left(\mathrm{UF}_{4}\right)$, magnesium is used to remove the fluorine atoms from the depleted $\mathrm{UF}_{4}$ (known as "reduction"). One process uses batch reduction (the standard industrial process); the other uses a continuous process.

Long-Term Storage. The PEIS includes two long-term storage alternatives: the first is storage as depleted $\mathrm{UF}_{6}$ and the second is storage as depleted uranium oxide. Options in the long-term storage module are the types of storage facility. Suboptions are the chemical forms of depleted uranium which might be stored in each type of facility. The following list shows the three storage facility options and the chemical forms of depleted uranium which are analyzed for each option:

1. Storage in a building:

$\mathrm{UF}_{6}, \mathrm{U}_{3} \mathrm{O}_{8}, \mathrm{UO}_{2}$

2. Storage in a below ground vault: $\mathrm{U}_{3} \mathrm{O}_{8}$ and $\mathrm{UO}_{2}$

3. Storage in a mine:

$\mathrm{UF}_{6}, \mathrm{U}_{3} \mathrm{O}_{8}, \mathrm{UO}_{2}$

Mamufacture and Use. Use of the depleted $\mathrm{UF}_{6}$ would require converting the material to an oxide or a metal and manufacturing an end product. Two alternatives for using depleted $\mathrm{UF}_{6}$ are included in the PEIS. In both of them, depleted uranium would be used to shield workers from the radiation from used-up, or spent, nuclear fuel (SNF) from power reactors.

In one use alternative, depleted $\mathrm{UF}_{6}$ would be converted to dense $\mathrm{UO}_{2}$ pellets, which could be substituted for the gravel in conventional concrete. Depleted uranium concrete, sometimes called DUCRETETM, would serve as a shielding material in SNF storage casks. The second use alternative would convert the depleted $U_{F_{6}}$ to metal and then make the depleted uranium metal into cylindricalshaped shields for a multi-purpose unit system. The multi-purpose unit would confine SNF during storage, transportation, and disposal.

Radiation shielding is just one of several possible uses of depleted uranium. Others are shown in Table 1 and are discussed in the Engineering Analysis Report and the Summary of the Engineering Analysis Report. Radiation shielding is representative of a number of potential uses. In addition to use in storage casks, there are other possible ways depleted uranium concrete might be used, for example, in a repository for spent nuclear fuel.

Disposal. Disposal of a material means that it should be isolated from the environment for the indefinite future. Uranium oxide, either $\mathrm{U}_{3} \mathrm{O}_{8}$ or $\mathrm{UO}_{2}$ is the only chemical form of depleted uranium analyzed for disposal. The oxide may be mixed with cement before disposal, or disposed of in bulk form inside drums. 
The disposal options analyzed are (1) disposal in an engineered trench, (2) disposal in a below ground vault, and (3) disposal in a mine. Each disposal facility option is evaluated for the same four waste form suboptions: (1) cemented $\mathrm{U}_{3} \mathrm{O}_{8}$, (2) cemented $\mathrm{UO}_{2},(3)$ bulk $\mathrm{U}_{3} \mathrm{O}_{8}$, and (4) bulk $\mathrm{UO}_{2}$. The range of cases reflects differences in the climate and geology of possible disposal sites. Differences in the chemical stability and release rates of the waste forms and the degree to which they would dissolve in water or disperse in air are also considered.

\section{Cost Estimation Methodology}

Cost estimates are based on engineering data from the Engineering Analysis Project and a set of consistent assumptions.

Cost estimates were developed for the options and suboptions in the unshaded blocks in Table 1, and for contimued cylinder storage/current management at the existing storage yards. Some technologies (for example, the batch process for conversion to metal) are currently used by industry; others (for example, the gelation process for conversion to oxide and the continuous process for conversion to metal) are being developed or have been tested only on a small scale. Most technologies would require significant engineering development.

\subsection{Schedule and Throughput Assumptions}

Schedule. The Draft PEIS examines the time period from the year 1999 to the year 2039. The Cost Analysis Report assumes the same time period, although activities could continue beyond 2039. A generic schedule was created for conversion and manufacturing facilities, with operations beginning about eleven years after the Record of Decision (expected in 1998). After the period of operation, which is assumed to last 20 years, decontamination and decommissioning would take three years. Table 2 summarizes the schedule for the activities in the alternatives. Relative costs of the various alternatives would be unaffected by a shift in the starting time.

Throughput. Throughput refers to the rate at which material is processed. Processing all 560,000 MT of depleted $\mathrm{UF}_{6}$ was assumed to take 20 years. Therefore, the throughput, or production rate, of the processing and manufacturing facilities was assumed to be 28,000 MT (60 million pounds) of depleted $\mathrm{UF}_{6}$ per year. The desired throughput defines the required size and capacity of the facilities. 
Table 2. Assumed Activity Schedule for Alternatives

\begin{tabular}{|c|c|c|c|c|c|c|}
\hline Activity & $\begin{array}{c}\text { No } \\
\text { Action }\end{array}$ & $\begin{array}{c}\text { Long- } \\
\text { Term } \\
\text { Storage as } \\
\text { Depleted } \\
\text { UF }\end{array}$ & $\begin{array}{l}\text { Long-Term } \\
\text { Storage as } \\
\text { Depleted } \\
\text { Uranium } \\
\text { Oxide }\end{array}$ & $\begin{array}{c}\text { Use as } \\
\text { Depleted } \\
\text { Uranium } \\
\text { Oxide }\end{array}$ & $\begin{array}{c}\text { Use as } \\
\text { Depleted } \\
\text { Uranium } \\
\text { Metal }\end{array}$ & $\begin{array}{c}\text { Disposal as } \\
\text { Depleted } \\
\text { Uranium } \\
\text { Oxide }\end{array}$ \\
\hline $\begin{array}{c}\text { Continued } \\
\text { Cylinder Storage } \\
\text { in Current Yards }\end{array}$ & 1999-2039 & $1999-2028^{2}$ & $1999-2028^{2}$ & $1999-2028^{2}$ & $1999-2028^{4}$ & $1999-2028^{\circ}$ \\
\hline $\begin{array}{c}\text { Cylinder } \\
\text { Preparation for } \\
\text { Shipment }\end{array}$ & & $2009-2028$ & $2009-2028$ & $2009-2028$ & $2009-2028$ & $2009-2028$ \\
\hline Transport $^{b}$ & & & 2009-2028 & 2009-2028 & $2009-2028$ & $2009-2028$ \\
\hline Conversion & & & 2009-2028 & 2009-2028 & 2009-2028 & $2009-2028$ \\
\hline $\begin{array}{l}\text { Emptied } \\
\text { Cylinder } \\
\text { Treatment }\end{array}$ & & & $2009-2028$ & $2009-2028$ & $2009-2028$ & $2009-2028$ \\
\hline Transport $^{\circ}$ & & & & $2009-2028$ & 2009-2028 & \\
\hline Manufacturing & & & & 2009-2028 & 2009-2028 & \\
\hline Transport $^{d}$ & & 2009-2028 & 2009-2028 & 2009-2028 & 2009-2028 & 2009-2028 \\
\hline $\begin{array}{l}\text { Long-Term } \\
\text { Storage }\end{array}$ & & $2009-2039$ & 2009-2039 & & & \\
\hline Use $^{e}$ & & & & 2009 & 2009 & \\
\hline Disposal & & & & & & $2009-2028$ \\
\hline
\end{tabular}

a. The amount of depleted $\mathrm{UF}_{6}$ in storage at the current sites decreases five percent per year beginning in the year 2009 until it is all gone in 2029.

b. Transport of depleted $\mathrm{UF}_{6}$ to conversion facility.

c. Transport of depleted uranium oxide or metal to a manufacturing facility.

d. Transport of depleted $\mathrm{UF}_{6}$, oxide, or metal to storage, use, or disposal sites. Transport and placement for the storage and disposal alternatives would occur between 2009 and 2028; 2029 to 2039 is a surveillance period.

e. Use as SNF storage casks begins in 2009.

\subsection{Cost Basis}

As noted in Section 2.1, the cost breakdown structure closely follows the work breakdown structure used in the engineering analysis. Figure 8 gives a close-up of the cost breakdown structure to Level 6 for one conversion suboption. Level 2 is the module (conversion); Level 3 is the option $\left(\mathrm{U}_{3} \mathrm{O}_{8}\right.$ ); Level 4 is the technology suboption (dry process with AHF by-product); and Level 5 breaks out seven major elements, from "technology development" to "decontamination and decommissioning" of the facility after operations are finished. Level 6 shows cost categories such as engineering, construction, materials, and labor for the Level 5 elements. 


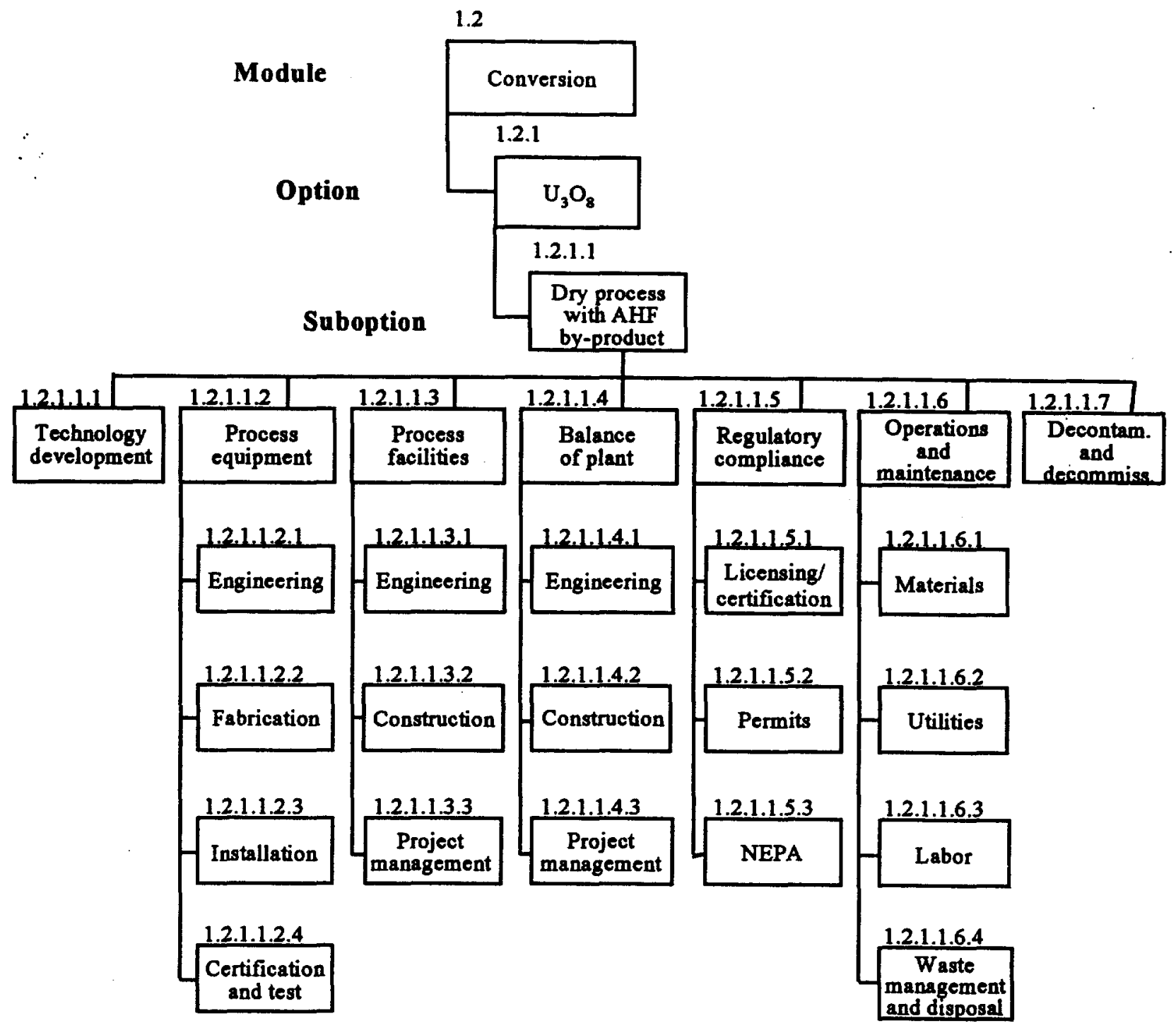

Figure 8. Cost Breakdown Structure to Level 6 for Conversion to $\mathrm{U}_{3} \mathrm{O}_{8}$ Using the Dry Process with Anhydrous HF Production

All of the management strategy alternatives were evaluated in terms of the net present value of all money outlays and returns, from technology development through decontamination and decommissioning. A discount rate of seven percent per annum was used for the reported costs.

For each management strategy alternative, there is a range of costs, depending on the costs of the particular options and suboptions which might be chosen to carry out the alternative. The following 


\section{What is a Discount Rate?}

For long-term projects, it is convenient to translate costs and benefits which will occur at different times into a common unit of measurement. A discount rate translates the future value of money into its present yalue. Seven percent per annum is the discount rate currently recommended by the Office of Management and Budget. paragraphs discuss the cost elements which were analyzed. These cost elements relate to the elements in Figure 8, Level 5 . In addition, potential revenues from the sale of byproducts are discussed.

Technology Development. The cost of technology development includes the costs for design verification and pilot tests before detailed design and engineering begin. The cost estimates are primarily based on engineering judgment. The focus is on relative

costs. Development and testing were assumed to take place in existing facilities which are able to handle large quantities of depleted uranium.

Facility Capital Costs. This category includes the costs for the elements "process equipment," "process facilities," "balance of plant," and "regulatory compliance" in Figure 8. Architect/engineering design costs are also included. The site cost was developed for a hypothetical, previously unused site. Labor rates and state sales taxes are based on a generic site. Direct construction costs include the cost of craft labor, construction materials, and installed equipment. Balance of plant costs include the costs of improvements to the site, utility and support buildings, and services.

Engineering contingencies which could affect costs were determined for the various options. It was assumed for all cases that there would be a development program which would confirm the feasibility of the process, demonstrate successful equipment operation, and produce the engineering data for scale-up to production size equipment. Contingencies reflect such factors as how developed the designs are and how much experience already exists with similar processes or equipment.

The cost estimating contingencies were applied to capital costs as follows:

- Process and manufacturing facilities:

- Balance of plant:

- Process and manufacturing equipment:
30 percent

20 percent

variable (30-50 percent, depending on technology)

Regulatory compliance includes preparing a site-specific environmental impact statement following the PEIS and acquiring state, local, and federal permits for air and water. Construction permits are also included in this category.

Qperations and Maintenance. The "materials" block under the operations and maintenance element in Figure 8 refers to all consumable materials used in process operations, such as chemicals and cements. Labor costs include salaries plus fringe benefits for the direct operations and maintenance staffs and the indirect staff (for example, medical personnel). Utility and general service costs for 
routine replacement items are taken as 10 percent of the total operating labor cost, or the actual cost if greater.

Waste handling and disposal costs are based on the following rates:

- Nonhazardous waste:

- Hazardous waste:

- Low-level radioactive waste:

- Mixed (radioactive/hazardous) waste:
$\$ 2 /$ cubic foot $\$ 20 /$ cubic foot $\$ 100 /$ cubic foot $\$ 100 /$ cubic foot

Decontamination and Decommissioning. It was assumed that facilities would be cleaned and left standing at the end of their operating period. The decontamination and decommissioning cost is taken as ten percent of the total facility capital costs.

By-Product Revemues. All of the conversion processes produce potentially salable by-products, either AHF or calcium fluoride $\left(\mathrm{CaF}_{2}\right)$. Sale of these by-products would partially off-set the costs described above. Revemues, or credits, of approximately $\$ 1500$ per MT of AHF and $\$ 100$ per MT of $\mathrm{CaF}_{2}$ are used in the cost analysis.

\subsection{Reference Case Assumptions}

So that the results for the many different options and suboptions could be compared, cost estimates were based on a sample case, or "reference case." Some of the major assumptions for the reference case are listed in Table 3.

\section{Table 3. Major Assumptions for Reference Case}

\footnotetext{
- Total amount of depleted UF $_{6}: \quad 560,000 \mathrm{MT}$ (over a billion pounds)

- Total number of cylinders in current storage:

46,422 cylinders

- Annual throughput:

$28,000 \mathrm{MT}$ ( 60 million pounds) of depleted $U_{6}$ per year

- Discount rate: seven percent per annum

- Number of nonconforming cylinders requiring special preparation for shipment:

29,083 cylinders

- Transportation distance: $1000 \mathrm{~km}$ (620 miles) per trip

- By-products ( $\mathrm{AHF}$ and $\mathrm{CaF}_{2}$ ) would be sold.

- Potential revenue from sale of shielding casks is considered separately.
} 
To provide a more complete cost analysis, estimates using different assumptions were also calculated for some options (see Section 6.1 of this Summary).

\section{Cost Estimation of Options}

Costs were estimated for all the options and suboptions analyzed in depth in the Engineering Analysis Report.

The Cost Analysis Report provides costs according to the cost breakdown structure. Table 4 presents a summary of the projected costs for options and suboptions (organized by the modules in the cost breakdown structure). This information is discussed in the paragraphs following Table 4.

The costs in Table 4 are median estimates (that is, there is a 50 percent chance that the costs will be higher and a 50 percent chance that costs will be lower than the estimates). Estimates are given in millions of first-quarter 1996 dollars discounted to the beginning of the project. The discount rate used for the reference case is seven percent per annum.

\section{Table 4. Summary of Cost Estimates for Options and Suboptions}

\begin{tabular}{|c|c|}
\hline Options/Suboptions & Discounted Cost (in S million) \\
\hline $\begin{array}{l}\text { Continued Cylinder Storage in current yards } \\
\text { - No Action alternative } \\
\text { - Other alternatives }\end{array}$ & $\begin{array}{l}327 \\
197\end{array}$ \\
\hline $\begin{array}{l}\text { Transportation } \\
\text { - "Low": overcontainer suboption for cylinder preparation } \\
\text { option and rail transportation option } \\
\text { - "High": transfer facility suboption for cylinder } \\
\text { preparation option and truck transportation option }\end{array}$ & $\begin{array}{l}172-202^{2} \\
677-712^{2} \\
\end{array}$ \\
\hline 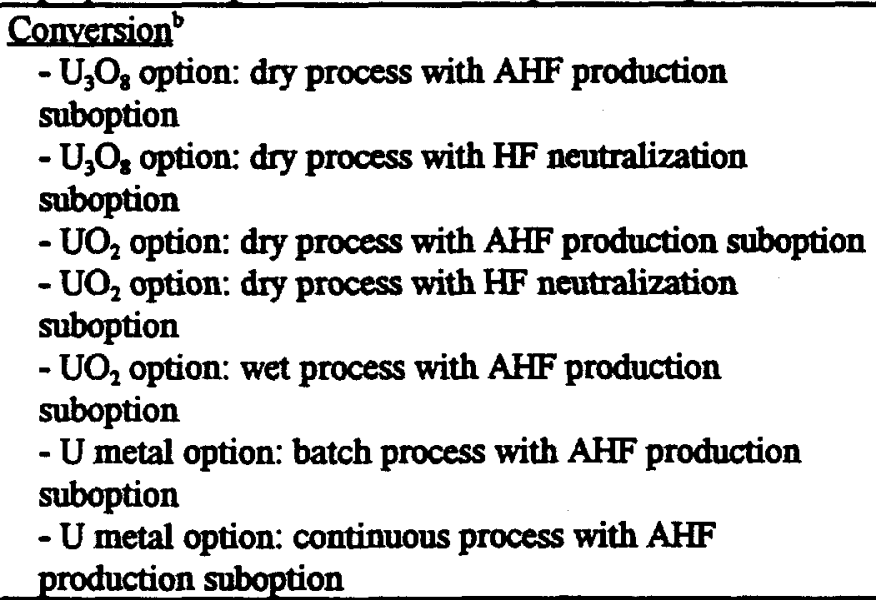 & $\begin{array}{l}267 \\
325 \\
347 \\
395 \\
\\
821 \\
665 \\
492\end{array}$ \\
\hline $\begin{array}{l}\text { Use } \\
\text { - Radiation shielding option: uranium oxide suboption } \\
\text { - Radiation shielding option: uranium metal suboption }\end{array}$ & $\begin{array}{l}856 \text { (without credits for sale of casks) } \\
889 \text { (without credits for sale of casks) }\end{array}$ \\
\hline
\end{tabular}




\begin{tabular}{|l|l|}
\hline \multicolumn{1}{|c|}{ Options/Suboptions } & Discounted Cost (in S million) \\
\hline Long-Term Storage & \\
\hline - Building option: $\mathrm{UO}_{2}$ suboption & $147^{\circ}$ \\
- Building option: $\mathrm{U}_{3} \mathrm{O}_{8}$ suboption & 225 \\
- Vault option: $\mathrm{UO}_{2}$ suboption & $152^{\circ}$ \\
- Vault option: $\mathrm{U}_{3} \mathrm{O}_{8}$ suboption & 237 \\
- Mine option: $\mathrm{UO}_{2}$ suboption & $483^{\circ}$ \\
- Mine option: $\mathrm{U}_{3} \mathrm{O}_{8}$ suboption & 731 \\
\hline Disposal & \\
- Engineered trench option: bulk $\mathrm{UO}_{2}$ suboption & $123^{d}$ \\
- Engineered trench option: cemented $\mathrm{U}_{3} \mathrm{O}_{8}$ suboption & 433 \\
- Vault option: bulk $\mathrm{UO}_{2}$ suboption & $153^{d}$ \\
- Vault option: cemented $\mathrm{U}_{3} \mathrm{O}_{8}$ suboption & 647 \\
- Mine option: bulk $\mathrm{UO}_{2}$ suboption & $619^{d}$ \\
- Mine option: cemented $\mathrm{U}_{3} \mathrm{O}_{2}$ suboption & 1395 \\
\hline
\end{tabular}

a. Range reflects differences in transportation requirements among the various management strategy alternatives.

b. All conversion costs include credit for the sale of AHF produced by the AHF production suboption or the $\mathrm{CaF}_{2}$ resulting from the $\mathrm{HF}$ neutralization suboption.

c. Based on $\mathrm{UO}_{2}$ produced by the wet (gelation) conversion suboption. Storage cost for depleted $\mathrm{UF}_{6}$ (in a building or mine) lies between the costs for $\mathrm{UO}_{2}$ and $\mathrm{U}_{3} \mathrm{O}_{8}$.

d. Based on $\mathrm{UO}_{2}$ produced by the wet (gelation) conversion suboption. Disposal costs for bulk $\mathrm{U}_{3} \mathrm{O}_{3}$ and cemented $\mathrm{UO}_{2}$ lie between costs for bulk $\mathrm{UO}_{2}$ and cemented $\mathrm{U}_{3} \mathrm{O}_{8}$ for each of the disposal facility options.

Continued cylinder storage in the current yards occurs over the entire time period for the No Action alternative. For other alternatives, fewer cylinders are stored over a shorter period of time (see Table 2 , footnote "a"). Therefore, the "continued cylinder storage" cost for the No Action alternative is higher.

Transportation cost is the sum of the cylinder preparation cost (using an overcontainer or a transfer facility for nonconforming cylinders), loading and unloading costs, the actual shipping costs (by truck or by rail), and the emptied cylinder treatment cost. The substantial difference between the "low" case and the "high" case primarily reflects the much higher cost of the transfer facility suboption compared to the overcontainer suboption. The transfer facility suboption would involve the construction and operation of major new facilities.

Both transportation cases assume that there will be approximately 29,000 nonconforming cylinders and approximately 17,000 conforming cylinders. For costs based on different numbers of nonconforming and conforming cylinders, see Table 6.

The cost of using the dry process option for converting depleted $\mathrm{UF}_{6}$ to either depleted $\mathrm{U}_{3} \mathrm{O}_{8}$ or depleted $\mathrm{UO}_{2}$ is estimated for two suboptions for each oxide form. One suboption produces an AHF by-product and the other neutralizes the $\mathrm{HF}$ to produce $\mathrm{a} \mathrm{CaF}_{2}$ by-product. The higher market value of AHF compared to $\mathrm{CaF}_{2}$ explains the cost difference between the two suboptions. Dry process 
conversion to $\mathrm{UO}_{2}$ requires more steps than dry process conversion to $\mathrm{U}_{3} \mathrm{O}_{8}$ and therefore has higher costs.

Gelation, the wet process analyzed for conversion to small $\mathrm{UO}_{2}$ spheres, is more complex than dry process conversion and therefore has a higher estimated cost. However, recycling the chemicals used in the process would significantly improve the economics of the gelation process.

The batch process suboption for producing depleted uranium metal is estimated to cost significantly more than the continuous process suboption. This is primarily because the batch process has a lower processing rate and requires more equipment. However, batch reduction is a mature process, while the continuous process is currently being developed.

The differences in the costs of suboptions for both long-term storage and disposal primarily reflect the different densities of the depleted uranium storage and disposal forms. A denser form generally costs less because it requires less space. The tiny, dense spheres of depleted $\mathrm{UO}_{2}$ produced by the wet process have highest bulk density of the oxides. For the disposal options, a cemented waste form takes up more space because concrete is added to the depleted uranium oxide. Cementing also requires the construction and operation of a special facility.

\section{Cost Estimation of Management Strategies}

The estimated costs of management strategy alternatives are obtained by adding together the costs of the options which make up the strategies.

Table 5 presents the cost ranges for the six alternatives analyzed in the PEIS. Two cost ranges are given for the four alternatives involving conversion to reflect the cost differences between conversion suboptions.

Table 5. Summary of Cost Estimates for Alternatives

\begin{tabular}{|c|c|}
\hline Alternative & Discounted Cost (in $\mathbf{S}$ million) \\
\hline 1. No action & 327 \\
\hline 2. Long-Term Storage as UF & $583-1518$ \\
\hline $\begin{array}{l}\text { 3. Long-Term Storage as Oxide } \\
\text { - Using dry process }\left(\mathrm{U}_{3} \mathrm{O}_{8}\right) \text { with AHF production } \\
\text { - Using wet process }\left(\mathrm{UO}_{2}\right) \text { with AHF production }\end{array}$ & $\begin{array}{l}880-1897 \\
1356-2203\end{array}$ \\
\hline $\begin{array}{l}\text { 4. Use as Oxide }\left(\mathrm{UO}_{2}\right) \text { in Shielding Casks } \\
\text { - Using dry process with AHF production } \\
\text { - Using wet process with AHF production }\end{array}$ & $\begin{array}{l}1600-2112 \\
2075-2585\end{array}$ \\
\hline $\begin{array}{l}\text { 5. Use as Metal in Shielding Casks } \\
\text { - Using continuous process with AHF production } \\
\text { - Using batch process with AHF production }\end{array}$ & $\begin{array}{l}1780-2290 \\
1953-2463\end{array}$ \\
\hline $\begin{array}{l}\text { 6. Disposal as Oxide } \\
\text { - Dry process }\left(\mathrm{U}_{3} \mathrm{O}_{8}\right) \text { with } \mathrm{AHF} \text { production } \\
\text { - Wet process }\left(\mathrm{UO}_{2}\right) \text { with } \mathrm{AHF} \text { production }\end{array}$ & $\begin{array}{l}810-2561 \\
1332-2550\end{array}$ \\
\hline
\end{tabular}


In Table 5, the lower cost estimates in the ranges assume the following:

(1) Transportation is by rail.

(2) Cylinder preparation for shipment uses the overcontainer suboption.

(3) Long-term storage of depleted $\mathrm{UF}_{6}, \mathrm{U}_{3} \mathrm{O}_{8}$, and $\mathrm{UO}_{2}$ is in a building.

(4) Disposal of $\mathrm{U}_{3} \mathrm{O}_{8}$ and $\mathrm{UO}_{2}$ is in the bulk form in an engineered trench.

The higher cost estimates in the ranges assume the following:

(1) Transportation is by truck.

(2) Cylinder preparation for shipment uses the transfer facility suboption.

(3) Long-term storage of depleted $\mathrm{UF}_{6}, \mathrm{U}_{3} \mathrm{O}_{8}$, and $\mathrm{UO}_{2}$ is in a mine.

(4) Disposal of $\mathrm{U}_{3} \mathrm{O}_{8}$ and $\mathrm{UO}_{2}$ is in the cemented form in a mine.

When comparing the costs of alternatives in Table 5, the following should be kept in mind.

- The alternatives have different end points. Only the disposal alternative results in final disposition of the depleted uranium.

- With the exception of the No Action alternative, all alternatives have significant transportation costs. The size of this cost depends primarily on whether the overcontainer or the transfer facility suboption is selected for preparing nonconforming cylinders for shipment.

- With the exception of the No Action alternative and the long-term storage as depleted UF ${ }_{6}$ alternative, all alternatives include significant costs for the construction and operation of new facilities to convert depleted $\mathrm{UF}_{6}$ to an oxide or a metal form.

- With the exception of the No Action alternative, all alternatives include significant costs for the construction and operation of facilities for storage, manufacture, or disposal.

- Credits for the sale of shielding casks manufactured in the use alternatives will be included in later estimates. In the meantime, estimates (discounted) of potential revenues were made and are located in Section 6.1 of this Summary. These estimates indicate that there could be a significant reduction in the net cost for the use alternatives.

\section{Analysis of Sensitivities, Risks, and Vulnerabilities}

In addition to the reference cases, cases based on different assumptions were also analyzed.

\subsection{Sensitivity Analysis}

This analysis examines how the cost estimates might be affected by changes in the discount rate, transportation distance, shielding cask values, product density, and facility throughput.

Discount Rate. The reference cases use a discount rate of seven percent per annum. The effects of discount rates of four percent per annum and 15 percent per annum are also analyzed. The absolute 
values change substantially from the reference case, but the cost ranking of the strategies is largely unaffected by the use of these different discount rates.

Transportation Distance. The Cost Analysis Report and the Draft PEIS assume a standard transportation distance of $1000 \mathrm{~km}$ (620 miles) between facilities located at different sites. The cost ranking of the management strategies remains the same, even if this distance is changed to $500 \mathrm{~km}$ or $2000 \mathrm{~km}$ (using rail transportation with the overcontainer suboption for cylinder preparation). This is consistent with the finding that loading, shipping, and unloading account for less than one quarter of total transportation cost. A much greater portion of transportation cost is due to cylinder preparation, which is independent of shipping distance.

Shielding Cask Value. If depleted uranium metal or oxide were manufactured into shielding casks for storing SNF, some price could be charged for the casks. This charge would off-set some of the costs of the use alternatives. This potential revenue should be taken into account, just as revenue from the sale of $\mathrm{AHF}$ and $\mathrm{CaF}_{2}$ is taken into account.

There are a number of uncertainties, but an initial analysis was based on current estimated costs for two types of conventional concrete casks. These estimates are $\$ 150,000$ and $\$ 200,000$ per cask. The present value of these potential credits in millions of dollars would be 362 and 483 for the oxide shielding alternative and 342 and 456 for the metal shielding alternative. Other potential cost benefits, including eventual disposal with the SNF, are speculative at this time.

$\mathrm{UO}_{2}$ Product Density The costs for the $\mathrm{UO}_{2}$ storage and disposal options, and their associated management strategy alternatives, are based on a wet process (gelation) for converting depleted $\mathrm{UF}_{6}$ to dense $\mathrm{UO}_{2}$. The gelation process produces tiny spheres with a higher bulk density than other industrial processes, inchuding the $\mathrm{UO}_{2}$ dry process, which produces pellets. The smaller particle size minimizes the storage and disposal costs for the oxide. However, as shown in Table 4, the wet process has a much higher cost than the dry processes. Thus, the overall costs for the storage and disposal alternatives based on $\mathrm{U}_{3} \mathrm{O}_{8}$ can be significantly lower.

Approximations were used to estimate the long-term storage and disposal costs for $\mathrm{UO}_{2}$ pellets. $\mathrm{UO}_{2}$ pellets have a bulk density and conversion cost between those for $\mathrm{U}_{3} \mathrm{O}_{8}$ and those for $\mathrm{UO}_{2}$ spheres produced by the wet process. The costs for bulk $\mathrm{UO}_{2}$ pellets and bulk $\mathrm{U}_{3} \mathrm{O}_{8}$ powder are essentially the same for the storage and disposal alternatives.

Facility Throughput. Each option was evaluated at the same annual throughput rate of $28,000 \mathrm{MT}$ (about 60 million pounds) of depleted $\mathrm{UF}_{6}$, assuming that a single alternative would be selected. It is possible, however, that a combination of alternatives may be selected, or that multiple sites may be used for the same option. Therefore, several options were analyzed assuming facilities sized for 50 percent and 25 percent of the reference case. These smaller facilities were assumed to operate on the same schedule as the reference case and over the same 20-year period. 
The resulting cost reductions were less than the throughput reductions. For example, for the conversion options, a 50-percent reduction in throughput resulted in an average cost reduction of only about 16 percent. This general result would be expected on the basis of economy-of-scale considerations alone; however, the size of the difference depends strongly on the specific option or suboption.

\subsection{Performance Uncertainties}

This analysis estimates the cost impacts of uncertainties in the number of nonconforming cylinders and in process and facility designs.

Number of Nonconforming Cylinders. The number of depleted $\mathrm{UF}_{6}$ cylinders that will need special preparation to meet DOT regulations for offsite transportation is uncertain. Changes in the numbers of nonconforming cylinders would affect the costs of cylinder preparation for shipment.

The preliminary estimate of the number of nonconforming cylinders today (the reference case) is about 19,200 at Paducah; 5,200 at Portsmouth; and 4,683 (the entire inventory) at the East Tennessee Technology Park. For the purpose of the analysis, the "low" case is one-half of the preliminary estimate and the "high" case is all the cylinders. The Engineering Analysis Report includes early designs for cylinder transfer facilities with different production rates. Table 6 presents the estimated total costs for cylinder preparation for the reference, low, and high cases for both the overcontainer and the transfer facility suboptions.

Table 6. Cylinder Preparation for Shipment Costs (\$ million)*

\begin{tabular}{|l||l|l|l|}
\hline & $\begin{array}{c}\text { Reference Case } \\
(29,083 \text { Nonconforming } \\
\text { Cylinders) }\end{array}$ & $\begin{array}{c}\text { "Low" Case } \\
(14,542 \text { Nonconforming } \\
\text { Cylinders })\end{array}$ & $\begin{array}{c}\text { "High" Case } \\
(46,422 \text { Nonconforming } \\
\text { Cylinders })\end{array}$ \\
\hline Overcontainer & 161 & 148 & 171 \\
\hline Transfer Facility & 656 & 610 & 706 \\
\hline
\end{tabular}

* Sum of costs for preparing both conforming and nonconforming cylinders. (The high case assumes that all cylinders are nonconforming.)

Process and Facility Uncertainties. Uncertainties in facility and process scope cover those factors that are usually beyond the contractor's or the architect/engineer's control or outside the scope of the original design, schedule, and cost estimate. Costs have been estimated for various equipment additions and improvements that might be needed in the future to correct deficiencies in processing rate or the quality of products or by-products.

The potential increases in process equipment costs and associated facility costs are estimated for the transfer facility and for selected conversion facilities. Potential increases range from less than 10 percent of the original cost to nearly 40 percent of the original cost, depending on the technology. 


\subsection{Process Vulnerabilities}

The impact of changes in assumptions about what would be done with by-products is estimated for the oxide conversion processes producing major quantities of $\mathrm{CaF}_{2}$ and the metal conversion processes producing major quantities of magnesium fluoride $\left(\mathrm{MgF}_{2}\right)$.

Disposal of $\mathrm{CaF}_{2} \mathrm{By}$-Product from $\mathrm{HF}$ Neutralization Suboptions. All of the conversion options produce potentially salable by-products, either $\mathrm{AHF}$ or $\mathrm{CaF}_{2}$. Of the two, AHF would bring the higher price. However, in the unlikely event that the AHF were unsalable, the concentrated HF would be neutralized with lime to form $\mathrm{CaF}_{2}$. The reference case assumes that the $\mathrm{CaF}_{2}$ could be sold as a feedstock for producing AHF. The reference case cost estimate appears in Table 4.

Barring sale, the $\mathrm{CaF}_{2}$ is assumed to be disposed of as a nonhazardous solid waste. This case would result in a large waste stream, approximately equal to the amount of depleted $\mathrm{UF}_{6}$ converted. A major potential vulnerability is that the small amount of uranium in the $\mathrm{CaF}_{2}$ may require it to be disposed of as a low-level radioactive waste.

Table 7 compares the costs of oxide conversion with HF neutralization for cases in which the $\mathrm{CaF}_{2}$ is sold (the reference case), disposed of as nonhazardous solid waste, and disposed of as low-level waste.

Table 7. Cost Impacts of Disposal of $\mathrm{CaF}_{2}$ on Conversion Suboptions with HF Neutralization ( $\$$ million)

\begin{tabular}{|l||l|l|l|}
\hline \multicolumn{1}{|c|}{ Suboption } & $\begin{array}{c}\text { Reference Case: } \\
\text { Sale of } \mathrm{CaF}_{2}\end{array}$ & $\begin{array}{c}\text { Disposal of CaF } \\
\text { Nonhazardous Solid Waste }\end{array}$ & $\begin{array}{c}\text { Disposal of CaF } \\
\text { Low-Level Waste }\end{array}$ \\
\hline $\begin{array}{l}\mathrm{U}_{3} \mathrm{O}_{8} \text { with } \mathrm{HF} \\
\text { Neutralization }\end{array}$ & 325 & 340 & 544 \\
\hline $\begin{array}{l}\mathrm{UO}_{2} \text { with } \mathrm{HF} \\
\text { Neutralization }\end{array}$ & 395 & 409 & 614 \\
\hline
\end{tabular}

Disposal of $\mathrm{CaF}_{2}$ as nonhazardous solid waste would result in a modest cost increase over sale. However, disposal of $\mathrm{CaF}_{2}$ as low-level waste would result in a major cost increase over both sale and disposal as a nonhazardous solid waste.

Disposal of $\mathrm{MgF}_{2}$ By-Product from Metal Conversion Options. The metal conversion process produces major quantities of $\mathrm{MgF}_{2}$ (equal to approximately one-half the amount of depleted $\mathrm{UF}_{6}$ converted). The reference case assumption for both metal conversion processes is that the $\mathrm{MgF}_{2}$ could be disposed of as a nonhazardous solid waste. The reference case cost estimates appear in Table 4.

Exemptions for $\mathrm{MgF}_{2}$ with low levels of uranium have been granted, but the quantities of $\mathrm{MgF}_{2}$ were much smaller than the quantities expected here. The extent of $\mathrm{MgF}_{2}$ decontamination possible is uncertain, but the levels of uranium remaining in $\mathrm{MgF}_{2}$ are likely to be at least ten times greater than 
those in the $\mathrm{CaF}_{2}$ from $\mathrm{HF}$ neutralization. Therefore, $\mathrm{MgF}_{2}$ is considered more vulnerable than $\mathrm{CaF}_{2}$ to a requirement for disposal as low-level waste.

Table 8 shows the effect of disposal of $\mathrm{MgF}_{2}$ as low-level waste on the costs for the metal conversion suboptions. As with $\mathrm{CaF}_{2}$, disposal as low-level waste results in a major cost increase over disposal as nonhazardous solid waste.

Table 8. Cost Impacts of Disposal of $\mathbf{M g F}_{2}$ on Metal Conversion Suboptions ( $\$$ million)

\begin{tabular}{|l||l|l|}
\hline \multicolumn{1}{|c|}{ Suboption } & $\begin{array}{c}\text { Disposal of } \mathrm{MgF}_{2} \text { as Non- } \\
\text { hazardous Solid Waste }\end{array}$ & $\begin{array}{c}\text { Disposal of } \mathrm{MgF}_{2} \text { as Low- } \\
\text { Level Waste }\end{array}$ \\
\hline Batch rectuction process & 665 & 745 \\
\hline Contimuous rectuction process & 492 & 600 \\
\hline
\end{tabular}




\section{References}

Dubrin, J.W., et al. Engineering Analysis Report for the Long-Term Management of Depleted Uranium Hexafluoride. UCRL-AR-124080. Lawrence Livermore National Laboratory. May 1997.

Elayat, H., J.N. Zoller, and L. Szytel. Cost Analysis Report for the Long-Term Management of Depleted Uranium Hexafluoride. UCRL-AR-127650. Lawrence Livermore National Laboratory. May 1997.

U.S. Department of Energy. Draft Programmatic Environmental Impact Statement for Alternative Strategies for the Long-Term Management and Use of Depleted Uranium Hexafluoride. December 1997. 


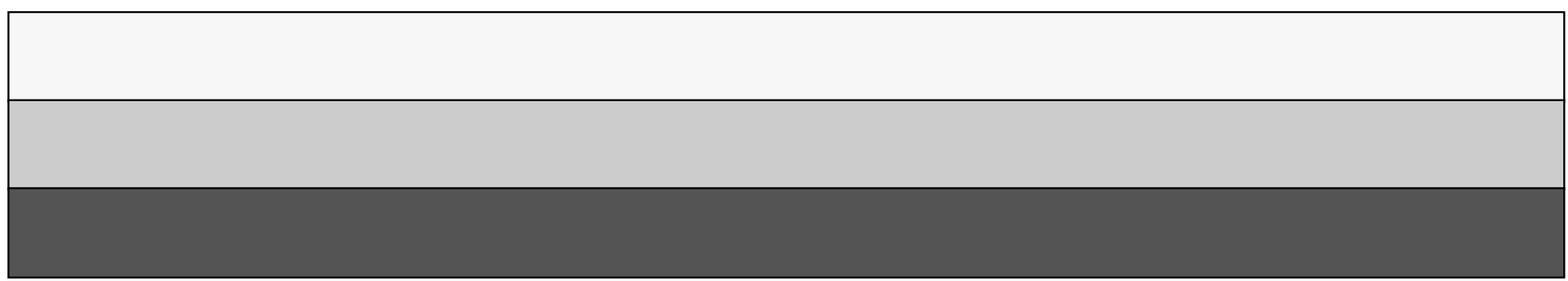

